\title{
EL LUGAR DE LA AUTOMATIZACIÓN EN EL CAPITALISMO ACTUAL Y SUS PROYECCIONES EMANCIPATORIAS
}

\section{THE PLACE OF AUTOMATION IN CURRENT CAPITALISM AND ITS EMANCIPATORY PROJECTIONS}

\author{
Nicolás G. PAgura \\ Universidad de Buenos Aires \\ nicolas_pagura@yahoo.com.ar
}

RECIBIDO: 04/08/2021

ACEPTADO: 29/10/2021

Resumen: El propósito de este artículo es contribuir al análisis del proceso de automatización considerando, en primer lugar, su lugar en la dinámica del capitalismo actual y, en segundo lugar, su posible articulación con un proyecto postcapitalista. Para esto, se recupera en particular el análisis de Marx, según el cual el desarrollo tecnológico está en el núcleo de la dinámica contradictoria de este sistema, vinculada tanto con el aumento del desempleo como con la baja tendencial de la tasa de ganancia. Si bien sus proyecciones parecieron ser refutadas en el siglo XX, particularmente en el período keynesiano-fordista de auge del pleno empleo, las mismas adquieren renovada actualidad hoy: en economías de bajo crecimiento, con sobrecapacidad industrial a nivel mundial y una distribución regresiva del ingreso que resiente la demanda, han dejado de funcionar muchos de los mecanismos que en el pasado contuvieron las tendencias contradictorias del capitalismo. El sistema, a pesar de sus efectos negativos en el entramado social, tiene la capacidad de seguir funcionando mientras no emerja un proyecto político alternativo. Por esto, urge reflexionar sobre la posibilidad de un proyecto postcapitalista articulado en torno de la automatización de la producción. Con este fin, en la última parte de este artículo se realiza una revisión crítica de las propuestas de Srnicek y Williams emblemas del llamado "Aceleracionismo de izquierda"- que plantean la necesidad de impulsar la automatización en vistas de la construcción de una sociedad postcapitalista.

Palabras clave: automatización; Marx; aceleracionismo; postcapitalismo 


\begin{abstract}
The purpose of this article is to contribute to the analysis of the automation process considering, firstly, its place in the dynamics of current capitalism and, secondly, its possible articulation with a post-capitalist project. For this, Marx's analysis is recovered, according to which technological development is at the core of the contradictory dynamics of this system, linked both to the increase in unemployment and to the tendency of the rate of profit to fall. Although his projections seemed to be refuted in the 20th century, particularly in the Keynesian-Fordist period of full employment, they take on renewed relevance today: in low-growth economies, with global industrial overcapacity and a regressive distribution of income, many of the mechanisms that in the past contained the contradictory tendencies of capitalism have ceased to function. The system, despite its negative effects at the social level, has the capacity to continue to function as long as an alternative political project does not emerge. For this reason, it is urgent to reflect on the possibility of a postcapitalist project articulated around the automation of production. To this end, the last part of this article makes a critical review of the proposals of Srnicek and Williams -emblems of the so-called "Left Accelerationism"- who raise the need to promote automation in view of the construction of a post-capitalist society.
\end{abstract}

Keywords: automation; Marx; Accelerationism; Post-capitalism

\title{
Introducción
}

En la segunda década del siglo XXI, particularmente al calor de los nuevos desarrollos en inteligencia artificial vinculados con la economía digital, se ha reactivado el debate sobre la automatización ${ }^{1}$ y el futuro del empleo. Si bien este tema ha estado presente prácticamente desde la revolución industrial, en las últimas décadas el mismo parece retornar periódicamente, lo cual sin lugar a dudas se vincula con el fuerte deterioro del mercado de

${ }^{1}$ En ocasiones, este término se utiliza en un sentido restringido, para aludir a un proceso o producto que se realiza con recursos tecnológicos y sin intervención alguna del hombre. Cabe aclarar que en este artículo utilizamos este término en un sentido más amplio, para aludir a toda innovación tecnológica que permita reducir -aunque sea de modo parcial- la cantidad de trabajo que requiere la producción de una mercancía determinada. 
trabajo que se vivencia en gran parte de las economías capitalistas especialmente desde fines de la década de 1970.

Simplificando al extremo el debate, puede decirse que en la discusión hay dos posturas en principio antagónicas. La primera de ellas sostiene que la introducción de tecnologías que aumentan la productividad tiende a incidir negativamente en el nivel de empleo, avizorando un crecimiento permanente de la desocupación que redundaría en la exclusión dramática de una franja de la sociedad de no tomarse las medidas necesarias para paliarla. Es la postura que, por ejemplo, sostuvo el economista norteamericano Jeremy Rifkin en El fin del trabajo (1996), libro publicado con amplia repercusión en 1995. Según Rifkin, la tercera revolución industrial -vinculada fundamentalmente con las tecnologías de la información y la comunicación- tiene un impacto directo sobre el empleo en la medida en que afecta a todos los sectores de la economía y particularmente al de los servicios, que anteriormente habría logrado absorber la mano de obra "liberada" en la industria (1996, pp. 175-176).

Los augurios sobre el desempleo tecnológico parecen haber vuelto en el segundo decenio del siglo XXI, con el amplio desarrollo de las tecnologías digitales vinculadas a la recolección y análisis de grandes cantidades de datos. Un informe bastante citado de 2013 señalaba, por ejemplo, que con la tecnología disponible se podían automatizar hasta el $47 \%$ de los empleos en EEUU (Frey y Osborne, 2013). Otro informe muy comentado del Banco Mundial extendía esta proyección a los llamados "países en vías de desarrollo", apuntando incluso una cifra mayor en estas regiones por su rezago tecnológico: dos tercios de los empleos podrían automatizarse y desaparecer (Banco Mundial, 2016, p. 23).

Otra postura niega que exista una relación lineal entre la mejora tecnológica de los procesos productivos y la destrucción del empleo. En relación a las proyecciones sobre los empleos que se 
automatizarían, algunos autores plantean que las mismas tienden a sobreestimar las cifras debido a varios supuestos erróneos. En esta línea, un informe de la OCDE de 2016 señala que numerosos vaticinios se basan en un enfoque equivocado, que proyecta directamente la automatización de tareas específicas a los empleos en sí, cuando estos últimos en general involucran una heterogeneidad de actividades anexas, no necesariamente automatizables. Con este recaudo, este informe concluye en una proyección sensiblemente más modesta, del $9 \%$ para los países de la OCDE (Arntz, Gregory y Zierahn, 2016). Pero el principal problema que se imputa a los pronósticos sobre el desempleo tecnológico radica en que implícitamente suponen una suerte de imperativo tecnológico según el cual del hecho de que un empleo o tarea sea técnicamente automatizable, se derivaría que se automatizará efectivamente en el futuro. Este supuesto desconocería factores que no son meramente técnicos, como la gradualidad y contingencia en la difusión y adopción de tecnologías disponibles, así como factores propiamente económicos, como el nivel de los salarios (que si son lo suficientemente bajos pueden desincentivar el proceso de automatización) y más en general las políticas macroeconómicas de los distintos países (Arntz, Gregory Zierahn, 2016; Figueroa, 2019).

Otro argumento contra la tesis del desempleo tecnológico plantea que la mejora tecnológica de los procesos de producción tiende a disminuir los precios de las mercancías, lo cual bajo ciertas condiciones puede implicar un aumento de la demanda y con ella de la creación de empleos vinculados dentro del rubro (Autor, 2015). Ya en su célebre La era de la información, cuya primera edición se publica en 1996, Manuel Castells generalizaba este argumento para discutir con Rifkin y otros autores que por entonces planteaban el advenimiento del fin del trabajo. Según él, estas tesis 
se equivocan al asumir un nivel fijo de demanda y de oferta de la producción, cuando "en el pasado, el rápido cambio tecnológico se ha solido asociar con una tendencia expansionista que, al aumentar la demanda y la producción, ha generado la necesidad de más jornadas en términos absolutos, aun cuando represente menos tiempo de trabajo por unidad de producción" (Castells, 2005, p. 317). En relación con esto, el sociólogo español agregaba otra cuestión clave que en general no es atendida en el análisis del tema: la inserción de la economía en el mercado mundial y la consecuente competencia internacional. La innovación tecnológica en un país permite aumentar su competitividad en el mercado mundial, lo cual redundaría, para el país en cuestión, en un aumento de la demanda externa y en la consiguiente creación de empleo (claro que la contrapartida podría ser la pérdida de empleo en la industria vinculada en el país menos competitivo). La conclusión de Castells, con todo, no era que el desarrollo tecnológico aumenta la demanda de empleo en todos los casos, sino que la cantidad de factores que entraban en juego para un análisis realista impedían establecer una relación estructural y unívoca entre ambas variables $(2005$, p. 320$)$.

Es posible encontrar también en el debate enfoques que -aunque puedan acordar con argumentos de algunas de las perspectivas señaladas- plantean la cuestión de la automatización en términos ético-políticos y no meramente fáctico-sociológicos. Según esta perspectiva, la automatización y el fin del trabajo serían los pilares de un proyecto socio-político posible antes que un destino inexorable ante el que habría que reaccionar de una u otra manera. La premisa básica de este proyecto sería la siguiente: si las tecnologías permiten aumentar la productividad, entonces habría que aprovecharlas para disminuir el tiempo de trabajo e incrementar el tiempo libre disponible para los sujetos. Esta idea, de hecho, posee un linaje que puede remontarse inclusive hasta la 
antigüedad griega. En Política, Aristóteles pudo imaginar que "si cada uno de los instrumentos pudiera cumplir por sí mismo su cometido obedeciendo órdenes o anticipándose a ellas, si (...) las lanzaderas tejieran solas y los plectros tocaran la cítara, los constructores no necesitarían ayudantes ni los amos esclavos" (2000, p. 1254a). Autores más cercanos a nuestra época plantearán que ya tendríamos las condiciones técnicas para cumplir al menos parcialmente con el sueño de Aristóteles, trascendiendo el reino de la necesidad, vinculado a la labor de cara a la satisfacción de las necesidades, en pos del reino de la libertad, que para el estagirita se vinculaba con el desenvolvimiento de actividades propias de la buena vida como la participación en la esfera política y la búsqueda de la sabiduría.

Esta última perspectiva subyace en distintos autores, desde Karl Marx en el siglo XIX hasta el reciente Aceleracionismo de izquierda, pasando por los planteos de André Gorz en las décadas de 1980 y 1990, entre otros. En estos enfoques, la automatización y la perspectiva del fin del trabajo se piensan a la luz de una crítica inmanente del capitalismo y, por lo tanto, en vistas de la articulación de un proyecto ético-político superador de este sistema.

El propósito de este artículo es contribuir al análisis del proceso de automatización considerando, en primer lugar, su lugar en la dinámica del capitalismo actual $\mathrm{y}$, en segundo lugar, su posible articulación con un proyecto poscapitalista. Para esto empezaremos revisitando, en el próximo apartado, algunos aspectos del análisis de Marx respecto de las relaciones entre desarrollo tecnológico y empleo, y el impacto de las mismas en la dinámica del capital. Entendemos que la contribución de este análisis para los debates actuales es decisiva, pues para Marx el desarrollo tecnológico es fundamental para entender tanto la dinámica contradictoria de este sistema como la necesidad de su superación. Sin embargo, le 
haremos algunas observaciones en vistas de actualizar su capacidad hermenéutica de cara a la elucidación de las dinámicas del capitalismo en el siglo XX. En esto último nos enfocaremos en el tercer apartado, donde caracterizaremos dos grandes períodos: el keynesiano-fordista en la posguerra, y el neoliberal desde mediados de la década de 1970. En buena medida, estos dos apartados buscan aportar concreción analítica al problema de la relación entre tecnología y empleo, primero abordando la cuestión con las herramientas teóricas que Marx legó para pensar el funcionamiento de un sistema económico determinado como es el capitalista, segundo revisando y utilizando estas herramientas para comprender algunas características de la fase actual de dicho sistema. Una de las consecuencias centrales que emergerán de este estudio será que la dinámica del mercado de trabajo en el capitalismo actual no puede comprenderse de ninguna manera considerando solamente el papel de la tecnología y su incidencia en la productividad, reduccionismo en el que en ocasiones caen los análisis sobre la automatización y su impacto en el empleo. Finalmente, en el cuarto apartado haremos una revisión crítica ya no vinculada al diagnóstico sino a lo que sería un proyecto político poscapitalista fundado en el desarrollo tecnológico y la automatización. Para eso, tomaremos como hilo conductor las propuestas de Srnicek y Williams, autores icónicos del llamado "Aceleracionismo de izquierda". 


\section{Apuntes sobre automatización, trabajo y capitalismo en Marx}

$\operatorname{Marx}^{2}$ parte de la teoría del valor proveniente de la economía política clásica, según la cual el valor de una mercancía se determina por el tiempo de trabajo socialmente necesario para producirla. En tanto, la esencia del capital es el plusvalor, cuya génesis es explicada por Marx del siguiente modo. En el mercado, el capitalista compra por su valor los elementos que necesita para poner en marcha el proceso productivo: materia prima, instrumentos de trabajo (entre ellos maquinaria) y fuerza de trabajo. El plusvalor surge del funcionamiento peculiar de esta última mercancía. El capitalista compra la fuerza de trabajo por su valor, es decir, el tiempo de trabajo socialmente necesario para reproducirla, que incluye el valor de los medios de subsistencia, así como el de su sustitución y formación. Pero en su funcionamiento efectivo (en su "consumo" en el proceso de producción) la fuerza de trabajo produce más valor que el necesario para su reproducción. La diferencia entre estas dos magnitudes es el plusvalor, que es lo que engendra el capital, que justamente es valor en proceso de acrecentamiento, valor que se valoriza en el proceso productivo. El período de la jornada laboral en el cual el obrero produce el valor equivalente a la fuerza de trabajo se denomina tiempo de trabajo necesario, y aquel en el que produce plusvalor se denomina tiempo de plustrabajo (2003, pp. 260-261). Además, Marx denomina capital variable a la fuerza de trabajo, puesto que es el único elemento adquirido por el capitalista que en el proceso productivo engendra más valor que el que tiene cuando es adquirida; los otros elementos (materia prima, maquinaria, etc.) constituyen el capital constante, limitándose a transferir el valor

\footnotetext{
${ }^{2}$ La exposición que sigue de las categorías centrales de Marx es sumamente sintética pero busca al menos introducirlas para que el lector pueda seguir la lógica interna que guía su análisis.
} 
que ya poseen al momento de su compra en el producto final, sin variar de magnitud en el proceso.

Existen dos formas mediante las cuales el capital puede aumentar el plusvalor. La primera se consigue incrementando el tiempo de plustrabajo en términos absolutos -esto es, manteniendo inalterado el tiempo de trabajo necesario- siendo la extensión de la jornada laboral y la intensificación del ritmo del trabajo los medios fundamentales para conseguir este resultado. A este plusvalor se lo denomina absoluto. En contraposición, Marx denomina plusvalor relativo al que surge de una reducción del tiempo de trabajo necesario, esto es, de un abaratamiento del valor de la fuerza de trabajo. Este resultado sólo puede obtenerse por un incremento de la productividad del trabajo que redunde en un abaratamiento directo o indirecto de los bienes de consumo de la población obrera. En El capital, Marx estudia dos mecanismos fundamentales para la obtención de plusvalor relativo: la división del trabajo, que se desarrolla fuertemente en el período manufacturero (desde mediados del siglo XVI en Inglaterra) y la introducción de maquinaria a partir de la revolución industrial de fines del siglo XVIII, que inaugura lo que Marx denomina Gran industria. Es en esta instancia donde hay que tratar el problema de la automatización en Marx.

El planteo de Marx sobre el tema tiene numerosas aristas, pero aquí nos centraremos en el problema del impacto que la introducción de la tecnología tiene para el desenvolvimiento del capital y del mercado de trabajo. Su perspectiva resulta sumamente sugestiva para pensar la complejidad de las relaciones entre capital, trabajo y automatización, no sólo en el siglo XIX sino también y ante todo en la actualidad, como veremos más adelante.

Desde el punto de vista de los factores económicos que influyen en la adopción de innovaciones tecnológicas, Marx pone particular énfasis en el nivel de los salarios. Para el capitalista, lo que justifica 
la adopción de una maquinaria no es el hecho de que su valor sea menor al producido por el trabajo que reemplaza, ya que él paga solamente una porción de este último, la correspondiente al trabajo necesario, mientras que al plustrabajo se lo apropia gratuitamente. Es condición necesaria para la adopción, entonces, que el valor de la maquinaria sea menor al valor de la fuerza de trabajo que reemplaza (2003, p. 478). Este es un primer punto interesante a considerar en la discusión sobre la automatización, ya que para Marx la propensión del capitalista a introducir tecnología se topa con límites propios de este sistema, lo cual constituye un apoyo a la hipótesis (que veremos que hoy plantea por ejemplo el llamado "aceleracionismo") de que el capitalismo no sólo impulsa, sino que en parte también limita el desarrollo tecnológico.

Desde el punto de vista del proceso de valorización del capital, la introducción de nuevas tecnologías en la industria tiene dos tipos de efectos, unos coyunturales y de corto plazo, y otros estructurales y de largo plazo, que son los que le interesan particularmente a Marx -y a nosotros-. Los primeros tienen que ver con el privilegio que obtiene aquel capitalista que introduce por primera vez una maquinaria en un determinado proceso. Se trata, claro está, de la ventaja competitiva que le otorga el hecho de producir con un menor costo, o sea, mercancías que encierran menos valor que la media social (2003, pp. 495). El capitalista, que detenta así por un período una suerte de monopolio, puede vender al valor de mercado y apropiarse de una renta extraordinaria, o puede vender a un valor menor en busca de apropiarse de una cuota mayor del mercado en desmedro de sus competidores. Hay que señalar que Marx no se detiene mucho en este tema, que en el capitalismo de fines del siglo XX adquirirá mayor importancia considerando las guerras de patentes y las presiones internacionales para extender y consolidar los regímenes de propiedad intelectual. Desde la apreciación de que este "privilegio del innovador" tendrá un plazo 
acotado que cesará cuando algunos de los competidores adopten la tecnología en cuestión o una mejor -los que no lo hagan probablemente quedarán fuera del mercado- el pensador alemán se detiene en los efectos agregados y a largo plazo que la innovación tecnológica tendrá para el capital.

Una vez que el uso de una máquina se generaliza y el innovador pierde su privilegio, el valor de las mercancías producidas desciende hasta la nueva media social, signada ahora por la productividad ganada con la nueva máquina. Es aquí donde aparece uno de los planteos más interesantes y sugestivos de Marx respecto de la automatización. En un sentido, la reducción del valor de las mercancías disminuye el de la fuerza de trabajo, lo cual incrementa el plusvalor relativo y con él la tasa de explotación. Sin embargo, al mismo tiempo disminuye el número de obreros empleados por una cantidad de capital dada (esto es lo que se denomina aumento de composición orgánica del capital), y con ello el trabajo vivo, única fuente de nuevo valor. Marx refiere así a una contradicción inmanente al capital en tanto impulsor del desarrollo tecnológico:

resulta claro que la industria fundada en la maquinaria, por mucho que extienda el plustrabajo a expensas del trabajo necesario -gracias al acrecentamiento de la fuerza productiva del trabajo-, sólo genera ese resultado mediante la reducción del número de obreros ocupados por un capital dado. A una parte antes variable del capital, es decir, una parte que se convertía en fuerza viva de trabajo, la transforma en maquinaria, por tanto en capital constante que no produce plusvalor alguno (...) el empleo de la maquinaria para la producción de plusvalor implica una contradicción inmanente, puesto que de los dos factores del plusvalor suministrado por un capital de magnitud dada, un factor, la tasa del plusvalor, sólo aumenta en la medida en que el otro factor, el número de obreros, se reduce" (2003, p. 496). 
La introducción de tecnologías que aumentan la productividad, entonces, aumenta la tasa de explotación, pero con el efecto paradójico de disminuir la masa de plusvalor, aunque no en términos absolutos necesariamente, sino relativos: la proporción de la masa de valor invertida por un capital dado en capital constante (capital fijo particularmente) crece en relación a la invertida en capital variable -la fuerza de trabajo, única mercancía con la cualidad de generar nuevo valor o plusvalor-.

Esta contradicción lleva, según Marx, a profundizar la explotación, ahora bajo la modalidad del plusvalor absoluto:

es esta contradicción la que, a su vez, impele al capital, sin que el mismo sea consciente de ello, a una prolongación violenta de la jornada laboral para compensar, mediante el aumento no sólo del plustrabajo relativo sino del absoluto, la disminución del número proporcional de los obreros que explota $(\ldots)$ de ahí la paradoja económica de que el medio más poderoso para reducir el tiempo de trabajo se trastrueque en el medio más infalible de transformar todo el tiempo vital del obrero y de su familia en tiempo de trabajo disponible para la valorización del capital (2003, p. 497)

En este punto, Marx cita el texto de Aristóteles al que ya referimos, y con la ironía aguda que caracteriza su prosa apunta que "esos paganos no entendían nada de economía política ni de cristianismo. No comprendían que la máquina es el medio más seguro para prolongar la jornada laboral" (2003, p. 498).

Marx parece entender, así, que la contradicción central del capital -vinculada con el desarrollo tecnológico- lo lleva a incrementar la explotación y a empeorar incluso más las condiciones de vida de la clase trabajadora. Y en esta misma línea hay que entender el capítulo XXIII de El capital, donde Marx plantea la célebre tesis según la cual el movimiento del capital crea permanentemente un ejército industrial de reserva, justamente debido al aumento de la composición orgánica del capital. Esta tesis ha sido vinculada con la del pauperismo, es decir, la idea 
según la cual bajo el capitalismo resulta inexorable el empeoramiento de la situación de la clase obrera.

Es relevante tomar nota de cara a lo que veremos en el próximo apartado que este pesimismo marxiano respecto de las consecuencias sociales que el desarrollo tecnológico tiene en el capitalismo va a ser impugnado en el siglo XX a la luz de la mejora relativa de las condiciones de vida de los sectores asalariados, ante todo en los países desarrollados (Habermas, 1998, pp. 244-251; Robinson, 1973, pp. 170-171). Sin embargo, hay que señalar que las premisas del planteo marxiano son bastante menos deterministas de lo que a primera vista parecen ser sus conclusiones. En efecto, al principio del mismo capítulo XXIII, Marx plantea que la acumulación de capital implica masas mayores de capital lanzadas a la producción, y por ello mayor cantidad de obreros puestos a su servicio: "Acumulación del capital es, por tanto, aumento del proletariado" (2003, p. 761). Luego introduce la cuestión del aumento de la composición orgánica del capital en la propia dinámica de la acumulación, y junto con ella la tesis del ejército industrial de reserva. Pero aunque disminuya progresivamente la parte variable del capital, eso redundaría en una expulsión absoluta de obreros sí y sólo sí esa disminución no es compensada por una masa de capital proporcionalmente mayor lanzada a la producción. Esto último puede suceder, según admite el mismo Marx (2003, p. 783), si la acumulación se acelera fuertemente. ${ }^{3}$ En el próximo apartado explicaremos que esto

3 Sin embargo, él parece pensar -en parte con el aval empírico del comportamiento del capitalismo inglés del siglo XIX- que esta condición no podría sostenerse permanentemente durante un tiempo prolongado, estando sujeto el sistema a ciclos cortos de expansión y estancamiento-. Son estos ciclos los que en parte explican que en su planteo el ejército industrial de reserva tenga la función clave de estar disponible para el capital en los períodos de aceleración de la acumulación, manteniendo a raya los salarios incluso bajo estas condiciones. 
sucedió precisamente en el período de posguerra con el auge del pleno empleo en economías con fuerte crecimiento económico, y es también lo que dejó de suceder en el período posterior a la crisis de la década de 1970.

La automatización no afecta solamente al empleo, sino también y especialmente a la dinámica del mismo capital. En efecto, la forma de manifestación de la contradicción inmanente del capital que antes revisamos es la ley de la baja tendencial de la tasa de ganancia, que Marx postula en el Tomo III de El capital. La baja tendencial, en efecto, está vinculada directamente con la mayor composición orgánica del capital, esto es, al hecho de que a medida que avanza la automatización como medio para la apropiación de plusvalor relativo, el valor del capital constante que emplea una cantidad dada de capital tiende a ser mayor que el capital variable del que tiene que disponer (2007, cap. XIII). Como sólo este último, como ya vimos, puede crear valor adicional, y la ganancia en última instancia depende del plusvalor, su disminución relativa conlleva la baja de la tasa de ganancia.

Sin embargo, el análisis de Marx no es en absoluto mecánico ni lineal, cuestión que a la luz de la historia posterior del capitalismo vale la pena enfatizar. Por un lado, y como ya señalamos, considerando que el capital es un proceso de acumulación progresivo, la baja tendencial de la tasa de ganancia es acompañada por un aumento de la masa de ganancias. En otras palabras: aunque un monto de capital determinado pase a rendir menor tasa de ganancia, el proceso de acumulación hace que la masa de capital a invertir crezca, y con ello también el capital variable empleado y las ganancias, lo cual compensa al menos para los grandes capitales la baja de la tasa -esta es la razón por la cual también el autor vincula la ley de la baja tendencial con la creciente concentración del capital-. Por otro lado, y no menos importante, Marx señala una serie de causas que pueden contrarrestar cuando menos 
parcialmente los efectos de la ley (2007, cap. XIV), entre las cuales cabe mencionar algunas de particular importancia: 1) la elevación del grado de explotación de la fuerza de trabajo por la prolongación de la jornada laboral y la intensificación del trabajo (cuestión que, como vimos, ya se mencionaba en el Tomo I); 2) el abaratamiento de los elementos del capital constante, en la medida en que también es afectado por los aumentos de productividad; 3) la superpoblación relativa, sobre todo por su efecto depresor del salario, que favorece la permanencia de ramas de baja composición orgánica del capital; 4) El comercio exterior, que puede contrarrestar la baja tendencial de diversos modos, entre los cuales cabe mencionar la transferencia de valor que se efectúa desde los países menos desarrollados con menor composición orgánica a favor de los países desarrollados, con una composición orgánica mayor.

Aunque Marx parece suponer que las causas contrarrestantes no pueden neutralizar la ley completamente, sin embargo la exposición de su desarrollo (2007, cap. XV) no predice un movimiento lineal hacia una situación de crisis final, sino una tendencia contradictoria que engendra otros procesos también problemáticos para el proceso de acumulación. El aumento de la masa de las ganancias favorece la concentración de capitales y, sobre todo, tiende a generar crisis de sobreproducción, ya que estas masas crecientes de capital encuentran dificultades para realizarse en el mercado, en el marco de un sistema basado en relaciones sociales antagónicas que tienden a menguar la capacidad de consumo de una parte sustancial de la población (2007, p. 314). Estas crisis, a su vez, pueden contrarrestarse pero por otros procesos incluso más catastróficos para el capital (sobre todo, la destrucción del capital excedente).

Este planteo delinea un terreno fértil para plantear el problema de la automatización, equidistante de visiones simplistas, algunas 
de las cuales mencionamos en la introducción. La automatización no es un problema meramente coyuntural del capitalismo, que se solucionaría espontáneamente por la aparición de nuevos mercados e industrias, aunque ciertamente este es un mecanismo fundamental en el cual el capital se apoya para afrontar su contradicción y a la vez expandirse. Pero tampoco la automatización es una tendencia que linealmente lleva al fin del trabajo y al surgimiento de una sociedad poscapitalista, idea que soslaya la capacidad del capital para contrarrestar sus tendencias críticas. Por eso su teoría -cuando se la recupera enfatizando más sus rasgos de apertura a la interpretación situada y menos fetichizando $\mathrm{y}$ tomando aisladamente algunas de sus conclusiones, en muchos casos condicionadas por la lectura de la dinámica del capitalismo del siglo XIX - sigue vigente y aporta elementos fundamentales para comprender, también, la capacidad de supervivencia y renovación de este sistema en los siglos XX y XXI.

Leído de este modo no determinista, el planteamiento marxiano permite también postular la automatización en términos de una posibilidad ético-política que este sistema ciertamente abre, pero que no puede cumplimentar. El célebre "fragmento sobre las máquinas" de los Grundrisse es tal vez el texto más rico en este sentido. En él se plantea que el "sistema automático de maquinaria", fase desarrollada de la Gran industria, ahonda la brecha existente entre la riqueza efectiva -los valores de uso que satisfacen necesidades materiales- y el valor -la medida abstracta de la riqueza que predomina en el sistema capitalista-. Como la primera depende crecientemente del desarrollo científico tecnológico alcanzado por la especie humana -al que Marx refiere con el célebre concepto de General intellect-, el valor, que depende del tiempo de trabajo socialmente necesario, "aparece como una base miserable comparado con este fundamento, recién desarrollado, creado por la gran industria misma" (Marx, 2001, 2, 
p. 227). El capital persiste en esta "base miserable" porque de hecho es la fuente de su existencia, y así "su tendencia, empero, es siempre por un lado la de crear disposable time [tiempo disponible], por otro la de to convert it into surplus labour [convertirlo en plustrabajo]" (2001, 2, p. 232).

La automatización abre de este modo el horizonte de la emancipación más allá del capitalismo. Esta posibilidad es enunciada por Marx de un modo enfático en los siguientes términos:

Desarrollo libre de las individualidades y por ende no reducción del tiempo de trabajo necesario con miras a poner plustrabajo, sino en general reducción del trabajo necesario de la sociedad a un mínimo, al cual corresponde entonces la formación artística, científica, etc. de los individuos gracias al tiempo que se ha vuelto libre y a los medios creados para todos (...) La riqueza no es disposición de tiempo de plustrabajo sino tiempo disponible, aparte del usado en la producción inmediata, para cada individuo y para toda la sociedad" (2001, 2, p. 229).

Vista así, la historia del capitalismo en el siglo XX -que delinearemos en el siguiente apartado- es la de sus sucesivas reestructuraciones para contrarrestar su contradicción inmanente y así frustrar también esta perspectiva ético-política emancipatoria, que sin embargo cobrará nuevo vigor en este siglo XXI.

\section{Tendencias contradictorias y mecanismos de compensación: del fordismo al neoliberalismo}

En este apartado retomaremos algunas de las ideas de Marx que hasta ahora formulamos en términos puramente teóricos, y trataremos de concretizarlas e historizarlas, viendo especialmente algunos mecanismos mediante los cuales, desde mediados del siglo XX, el capital se ha enfrentado a la contradicción engendrada por la 
automatización y el espectro del "fin del trabajo". Sin embargo, esta tarea de concretización exige en cierta medida ir más allá de Marx, sin que eso implique renunciar a los conceptos que nos legó para comprender el capitalismo. La crítica de la economía política de Marx opera en un nivel de abstracción demasiado elevado que exige mayor concretización, y vimos que en ocasiones sus conclusiones se vinculan con las condiciones del capitalismo de mediados del siglo XIX que trataba de explicar. Además no permite per se dar cuenta de las reestructuraciones profundas que el capitalismo ha experimentado en su historia, que explican también su supervivencia hasta la actualidad. Teorías como la de las ondas largas (planteada por primera vez por el economista ruso Kondatriev hacia 1930 y reformulada por distintos autores como Braudel y Arrigui, entre otros) o la de los modos de acumulación/regulación de la Escuela francesa de la regulación han tratado de salvar este problema, planteando que en su historia el capitalismo se ha reestructurado, instaurando determinados regímenes tecnológicos y organizacionales, sectores productivos fundamentales e instituciones y reglas de funcionamiento que prevalecen durante un período de tiempo determinado. Las dinámicas contradictorias y los mecanismos de compensación estudiados por Marx no funcionarían en abstracto sino en el marco de estos regímenes.

Ya manifestamos que los discursos sobre la automatización y el fin del empleo adquieren mayor calibre aproximadamente a principios de la década de 1980, momento en el que comenzaban a palparse algunas consecuencias de la reestructuración del capitalismo iniciada a principios de la década anterior. Con esta reestructuración, el capitalismo abandonaba parcialmente el conjunto mecanismos de compensación y estabilización, junto con los acuerdos políticos de clase que los acompañaban, que habían signado el período de posguerra. En lo que sigue, haremos una 
caracterización de este primer período, su crisis y la reestructuración posterior. Atender a algunos aspectos de este proceso histórico es fundamental para encarar el problema actual de la automatización de un modo situado y no meramente con argumentos generales que suponen implícitamente premisas poco realistas.

Vimos que el análisis de Marx en El capital entiende que el capitalismo, en la medida en que tiende a aumentar la composición orgánica, conduce a la vez a la creación de un ejército industrial de reserva de magnitud creciente, acompañada de una mayor explotación y precarización de la clase trabajadora en su conjunto. Sin embargo, ya señalamos sobre este punto que las premisas del análisis de Marx no descartan la posibilidad de que bajo determinadas condiciones el incremento de la masa de capital compense con creces la reducción del capital variable. Esta mecánica, en parte, es la que consiguió consolidarse en el período de posguerra, en el cual el capitalismo logró articular un equilibrio para sortear sus tendencias contradictorias.

Como señalan Benanav y Clegg (2010, p. 594), Marx no previó el progresivo surgimiento, desde fines del siglo XIX, de una serie de industrias con una gran capacidad de absorción de capital y mano de obra que neutralizarían la declinación en la demanda de fuerza de trabajo por más de medio siglo. La producción en masa vinculada a distintas industrias productoras de bienes durables como el automóvil- fue la base del sólido y estable crecimiento económico en los llamados "treinta gloriosos". Sin embargo, el sistema necesitó varias décadas y acontecimientos traumáticos para llegar a consolidarse. Fue recién en la posguerra que el fordismo y el taylorismo, que desde principios de siglo habían permitido aumentar la escala de la producción incrementando la productividad, encontraron en las políticas keynesianas una forma de generar la demanda efectiva necesaria para realizar el valor de 
las mercancías. Este vínculo entre la industria a gran escala y las políticas de fomento del consumo tiene su fundamento en que, como ya preveía Marx en el Tomo III de El capital, el desarrollo del proceso de acumulación conlleva, en el marco de un sistema basado en relaciones antagónicas de clase, el problema de la realización del valor de las mercancías y el fantasma, siempre presente, de la sobreproducción. ${ }^{4}$ Ya el mismo Ford era consciente en parte de que si se producían grandes series de productos, se necesitaba que los propios obreros tengan una capacidad de compra más allá de la mera subsistencia, e instauró el famoso five dollars a day. Sin embargo, esta política corporativa -todavía demasiado sectorial y parcial- no sería suficiente para evitar el problema de la sobreproducción que, de hecho, se manifestaría violentamente en la crisis de 1929 (Coriat, 2001, p. 93).

Como clase social, la burguesía -salvo algunas excepcionessuele ser cortoplacista y tiende a desconfiar de las políticas que condicionan su acción en lo inmediato aunque puedan brindar beneficios en el mediano plazo. Seguramente la crisis, junto con el temor al socialismo que representaba la URSS, hayan servido como mecanismo disciplinador para que finalmente aceptara políticas keynesianas de expansión de la demanda: aumento de las retribuciones directas -salarios mínimos fijados mediante convenios colectivos, subsidios al desempleo, creación de empleo público, por ejemplo- e indirectas -seguridad social, servicios públicos, etc.- Lo cierto es que políticas como el New Deal de Roosvelt y posteriormente la consolidación del Estado social particularmente en Europa- contribuyeron decisivamente a la

${ }^{4}$ Este tema se aborda, aunque de un modo algo fragmentario, en el ya mencionado cap. XV -sobre el desarrollo de las contradicciones internas de la ley de la baja tendencial- particularmente en el tercer apartado, cuyo título incluso anticipa el problema central del keynesianismo: "Exceso de capital con exceso de población". 
estabilidad del sistema en el mediano plazo, generando poder de compra para encauzar la demanda de la producción en serie y evitar las tan temidas crisis de sobreproducción. Nacía entonces la llamada "sociedad de consumo", que para absorber la capacidad productiva excedente resultante de los aumentos de productividad requeriría producir también constantemente nuevas necesidades mediante mecanismos como la publicidad, la obsolescencia programada y la moda. Necesidades que también permitían el crecimiento de nuevas industrias que a su vez generaban empleo asalariado.

Ciertamente, también estos beneficios tenían una contrapartida para la clase asalariada: aceptar mecanismos de producción alienantes y rutinarios que atentaban contra los saberes de oficio y descualificaban el trabajo (Harvey, 2008, p. 150). Y, más en general, con la entrada en la sociedad de consumo se aceptaban también las gratificaciones conforme al sistema, que de este modo lograba colonizar también el tiempo de ocio. Quedaban excluidas entonces posibilidades como la reducción de la jornada laboral fijada desde hacía tiempo en ocho horas diarias en la mayor parte de los países- y el impulso de formas de producción y consumo por fuera de los dispositivos mercantiles.

Cabe agregar que los mecanismos para contener las tendencias contradictorias del capitalismo fueron numerosos y no se agotaron en los mencionados, vinculados fundamentalmente a la expansión de la demanda en el mercado interno. La misma expansión se asentó sobre la destrucción previa de capital (la forma violenta mediante la cual para Marx se elimina el capital excedente para luego reactivar el proceso de acumulación), un efecto aunado de la crisis de 1929 y de la segunda guerra mundial -no por casualidad la reactivación de la economía norteamericana varios años después de la crisis estuvo también vinculada a la industria de guerra-. La canalización de los excedentes para evitar la sobreproducción se 
realizo también mediante lo que David Harvey denomina mecanismos de desplazamiento espaciales -inversiones en el extranjero, por ejemplo la realizada con la ayuda de EEUU en la reconstrucción de los países derruidos por la guerra- y temporales -en infraestructura a largo plazo, fundamentalmente- (2008, p. 207). Por otro lado, el capitalismo de posguerra apeló ampliamente a varios mecanismos contrarrestantes de la baja tendencial estudiados por Marx en el capítulo XIV del Tomo III de El capital. Sin pretender exhaustividad, podemos mencionar a este respecto las políticas de economización del capital constante, que incluyen la inversión -fuertemente impulsada por el Estado- en infraestructura y una política de alcance global -comandada por EEUU, potencia hegemónica indiscutible del período- tendiente a abaratar los insumos energéticos y la materia prima, además de la intensificación de la explotación del trabajo mediante la producción serializada.

Sin caer en idealizaciones, no hay ninguna duda de que, al menos en los países desarrollados, la posguerra fue el período de oro del capitalismo. Un contexto que aunó fuertes incrementos de la productividad, tasas de crecimiento económico inéditas (del orden del 5\%), y estabilidad macroeconómica con una redistribución de la riqueza que, sin hacer peligrar la tasa de ganancia y la acumulación de capital, permitió mejorar el nivel de vida de una porción importante de la fuerza de trabajo (Rapoport y Brenta, 2010, p. 35).

Sin embargo, este período encontró su límite, algo que cabía esperar: la estabilidad del capitalismo no se debe a que logre eliminar sus tendencias contradictorias, sino a que consigue balancearlas y sopesarlas por un lapso de tiempo. Hacia fines de la década de 1960 y principios de la década de 1970, la crisis muestra sus síntomas manifiestos en la desaceleración del crecimiento económico y una creciente inflación (la llamada "estanflación"). Lo 
que operaba de fondo era un descenso de las tasas de ganancia producto de que los mecanismos de estabilización de posguerra se estaban agotando. El modelo tecnológico organizacional del fordismo comenzó a perder potencial para aumentar la productividad, lo cual se manifestaba en particular en la necesidad de invertir un monto creciente de capital para obtener un determinado aumento en la producción (Arceo, 2009, p. 14). Este fenómeno implica un encarecimiento progresivo del capital constante que acelera fuertemente la caída de la tasa de ganancia, lo cual inevitablemente resiente la inversión. Las tasas de ganancia también se vieron afectadas por los incrementos salariales, en particular los asignados en una década de fuerte movilización política y sindical como fue la de 1960 (Antunes, 2005, pp. 26-32; Boltanski y Chiapello, 2002, pp. 259-269), así como por la creciente competencia que para la industria estadounidense representó el desarrollo, décadas después de la segunda guerra mundial, de Japón y Europa. La decisión de la OPEP en 1973 de aumentar el precio del petróleo fue la chispa que faltaba para implosionar el sistema, ya que implicó de inmediato un encarecimiento de los insumos energéticos para todos los segmentos de la economía.

La etapa que se abre desde la década de 1980 está signada por un aumento de la desocupación -que de todas formas alcanza niveles muy elevados sólo en algunos países- una creciente precarización del trabajo y unos salarios que tienden a estancarse. ¿Cómo explicar este comportamiento? Los teóricos de la automatización tienden a atribuir gran parte de la responsabilidad al desarrollo de las tecnologías de la información y la comunicación y su impacto negativo en el empleo. Sin embargo, esta explicación no se sostiene. Los especialistas hace tiempo que son conscientes de que el impacto en la productividad de estas tecnologías es moderado y sumamente parcial. Ya en su célebre estudio sobre la 
sociedad de la información, Manuel Castells (2005, p. 116) reconocía que el incremento anual de la productividad en las economías más desarrolladas fue entre 1979 y 1993 de apenas la tercera parte $(1,5 \%)$ que en la década de $1960(4,3 \%)$. Y si se consideran las últimas dos décadas, los índices de productividad en los países desarrollados fueron bastante menores: entre el 0,8 y el $1 \%$ para el total de la economía en los países de la OCDE entre 2005 y 2019 (OCDE, 2019). Que la productividad aumente mucho más rápidamente en las empresas tecnológicas punteras (OCDE, 2015 , p. 3) pone de manifiesto el carácter sesgado y parcial tanto de los aumentos de productividad, como de los discursos que posan la mirada exclusivamente en estos sectores de vanguardia para hacer proyecciones sobre el conjunto de la economía.

Aaron Benanav (2019 y 2020) ofrece una explicación más satisfactoria. Según él, hay ciertamente una menor demanda de empleo, pero la misma no se debe per se a los aumentos de productividad derivados de la innovación tecnológica sino a la sobrecapacidad de la industria, signada por una fuerte competencia internacional. En el período de posguerra se desarrollaron progresivamente Europa y Japón, que pasaron a ser competidores de EEUU, y posteriormente avanzó la desindustrialización de las economías desarrolladas y la deslocalización de la industria hacia países en desarrollo con salarios bajos, particularmente en el sudeste asiático. La producción manufacturera a nivel mundial pasó de crecer a una tasa anual del 7,1\% en las décadas de 1950 y 1960 a una tasa del 3\% desde 1980, para crecer apenas 1,6\% desde la crisis de 2008 (Bananav, 2019, p. 28). Lo que habría entonces es un estancamiento de las industrias con gran capacidad de absorción de capital y mano de obra que habían florecido en la etapa anterior y que, también, habían neutralizado algunas de las tendencias críticas predichas por Marx. Por eso tras la crisis el capitalismo entró en una fase de bajo crecimiento económico en comparación con el 
período de posguerra, algo menos de la mitad en las décadas de 1980 y 1990, e incluso más bajas posteriormente.

Cabe señalar que en este contexto ocurre un viraje político en todo el mundo, que comienza con la revolución conservadoraneoliberal de Thatcher y Reagan en los ' 80 y se consolida en las décadas siguientes. Las políticas neoliberales dejaron de lado el objetivo keynesiano de alcanzar el pleno empleo, transformando a este último en variable de ajuste de otros, como la baja inflación. Además, promovieron abiertamente políticas de flexibilización del mercado de trabajo, que redundaron en la proliferación de formas "atípicas", en general precarias, de empleo: part time, temporario, por tarea, etc. Ambos fenómenos -sensible aumento de los índices de desempleo y creciente precarización laboral- junto con otros como el progresivo desmantelamiento del Estado de Bienestar, colaboraron en lo que era el objetivo fundamental: una reestructuración de la relación entre capital y trabajo, claramente favorable al primero. Así, la participación de los salarios en el PBI pasó en los países de la eurozona del $76,3 \%$ en 1975 al $66,2 \%$ en 2006; en EEUU, la caída empezó ya en 1970, pasando del 66\% en ese año al 54\% en 2006 (Rapoport y Brenta, 2010, pp. 140-144 y 164-168). En un contexto de escaso dinamismo económico, la recomposición de las tasas de ganancia se consiguió así mediante una mayor explotación de la clase trabajadora. Pero esta estrategia tiene un efecto regresivo sobre el ciclo económico, ya que tiende a deprimir la demanda y con ella el crecimiento económico. A la crisis de las hipotecas de 2008, por ejemplo, subyacen unos salarios estancados, ${ }^{5}$ así como una política poco sostenible en el largo

${ }^{5}$ El caso de los salarios en EEUU es emblemático en este sentido. En el período 1973-1997, la evolución de la renta familiar anual estuvo prácticamente paralizada $(0,6 \%$ promedio entre $1973-79,0,4 \%$ entre $1979-89$ y sólo $0,1 \%$ entre 1989-97, contra el 2,8\% del período de posguerra). Los trabajadores con menores remuneraciones llevaron la peor parte, experimentando una baja anual promedio del $0,4 \%$. La desigualdad aumentó notablemente en el período: medida por el 
plazo, basada en la recomposición de la demanda por medio del endeudamiento de los hogares.

Con la capacidad industrial saturada, el empleo se crea en las actividades de servicios, en su mayor parte en sectores de baja productividad y de alta intensidad de mano de obra (OCDE, 2019), con salarios en muchos casos menguados o estancados. Más que al "desempleo tecnológico", el capitalismo contemporáneo parece tender a una creciente polarización en el mercado de trabajo, con un sector que mantiene salarios elevados, y otro -en continuo crecimiento- de trabajadores precarios y mal pagos. La automatización agudiza esta tendencia (Autor, 2015, pp. 9-19) porque tiende a afectar a los empleos de ingresos medios (además del trabajo manufacturero, el administrativo y el de ventas) mientras que los nuevos se crean en la parte alta de la pirámide (técnicos, managers, profesionales) y mucho más en la baja (servicios personales, cuidado, limpieza, alimentación).

Así, como señalara oportunamente George Caffentzis, la contracara oscura del capitalismo high tech es la sobreexplotación del trabajo:

Para poder financiar la nueva "utopía" capitalista de lo "high-tech", y de las industrias necesitadas de capital de riesgo en las áreas de energía, informática e ingeniería genética, otra "utopía" capitalista debe ser creada: un mundo de producción basada en "trabajo intensivo", bajos salarios, distraído y difractado (...) En este momento crítico, como siempre en la historia del capital, un salto en la tecnología se financia con el pellejo de los obreros más privados de tecnología (Caffentzis, 2020, p. 86).

índice de Gini, pasó de 0,399 en 1967 a 0,45 en 1995 (Castells, 2006: 158-162). Esta tendencia, lejos de revertirse, se profundizó posteriormente, y más aún tras la crisis de 2008. 
El capitalismo neoliberal converge bastante con el análisis de $E l$ capital según el cual el aumento de la composición orgánica del capital tiende a ser compensado con una sobreexplotación del trabajo -en sectores de alta y más aún de baja composición orgánica- acompañada de un crecimiento del ejército industrial de reserva. Así, adquiere renovada vitalidad la forma de explotación más antigua estudiada por el economista alemán, la del plusvalor absoluto, vinculada con el incremento (en general encubierto) de las horas trabajadas, la intensificación del trabajo y la erosión lisa y llana de los salarios reales. ${ }^{6}$

Por esto, entendemos aquí que la llamada "crisis en el mundo del trabajo" se debe menos al carácter novedoso del proceso de automatización contemporánea que a un conjunto de factores económico-políticos actuando simultáneamente: niveles relativamente bajos -particularmente en comparación con el período de posguerra- de crecimiento económico, un desarrollo de la productividad y la inversión también menor y sesgado a algunos sectores productivos, y unas tasas de ganancia del capital que se sostienen particularmente gracias a la sobreexplotación de amplios sectores de la fuerza de trabajo a nivel global.

Los discursos sobre la automatización y el desempleo tecnológico se reeditan periódicamente a la luz de la visibilidad que adquieren determinados desarrollos tecnológicos conjuntamente con otros fenómenos sociales. A principios de la década de 1980, florecieron con la incipiente difusión de la informática y la robótica, el aumento de la desocupación y la aceleración del

\footnotetext{
${ }^{6}$ Esta tendencia sigue las líneas de una nueva división internacional del trabajo. Por ejemplo, algunos países, particularmente en el sudeste asiático, proveen mano de obra barata para el sector industrial, mientras América Latina encuentra serias dificultades para encarar una política de sustitución de importaciones en este contexto y se reprimariza, sobreexplotando sus recursos naturales (Arboleda, 2020: cap. 1) y generando empleos en sectores de servicios de baja productividad y con bajos salarios, en gran parte fuera de la economía formal.
} 
proceso de desindustrialización en algunos países desarrollados. A mediados de la década siguiente, fue el desarrollo de internet el que en buena medida reactivó estos discursos, que se apagaron súbitamente a principios del nuevo milenio con la explosión de la burbuja especulativa de las empresas tecnológicas, conocida como "la crisis de las punto com". Tras la nueva depresión que generó la crisis global de 2008, la que ha venido emergiendo como la nueva estrella tecnológica es la inteligencia artificial vinculada con el denominado Machine learning. Esta tecnología se basa en la extracción masiva de datos, su análisis, modelización y utilización posterior para realizar distintos tipos de predicciones. Las grandes empresas tecnológicas vienen desarrollando fuertemente $-\mathrm{y}$ también monopolizando, con los riesgos políticos, económicos y sociales que ello acarrea- esta tecnología.

Ahora bien: ¿Será de la mano del Machine learning que se cumplirá finalmente la promesa de un incremento radical de la productividad que efectivamente implique un paso de tipo cualitativo en el proceso de automatización? Eso dependerá de que efectivamente esta tecnología logre extenderse al conjunto de la economía, incluyendo aquellos sectores que vienen experimentando bajas tasas de aumento de la productividad, particularmente en los servicios. En otras palabras, y como plantean Dyer-Witheford, Kjosen y Steinhoff (2019, pp. 46-56) los nuevos desarrollos de tecnología artificial tendrían que transformarse en una condición general de la producción capitalista, tal como para Marx lo fue la maquinaria en el siglo XIX, lo cual en condiciones de globalización tendría que ocurrir a una escala mucho más amplia. Hay proyectos que parecen ir en ese sentido (el internet de las cosas, las llamadas "ciudades inteligentes", los vehículos sin conductor que prometen cambiar de raíz la industria del transporte y la logística, etc.) pero para que ocurra efectivamente la transformación cualitativa antedicha 
tendrían que dejar de ser promesas; tampoco alcanzaría con su aplicación parcial y sectorizada, sino que tendrían que convertirse en la infraestructura tecnológica generalizada de un nuevo capitalismo. La idea de que esto ocurrirá necesariamente se basa en un imperativo tecnológico determinista que aquí no compartimos en absoluto. Que suceda o no, y en qué medida, dependerá de factores tanto técnicos como económicos y políticos.

Además, incluso si eso sucediera, se abrirían distintos escenarios, y las posiciones actuales sobre la automatización, después de todo, tal vez no estén haciendo más que especular respecto de los mismos. Aquellos planteos según los cuales la automatización aumenta la demanda, fomenta el crecimiento, etc. parecen suponer que podría recrearse con esta nueva base tecnológica algo similar al capitalismo de posguerra, una hipótesis que resulta algo improbable si se consideran las transformaciones estructurales acaecidas desde entonces. Más probable parece una simbiosis de esta economía high-tech monopolizada por unas pocas multinacionales con el trabajo precario, algo que de hecho se observa ya con la expansión de distintas plataformas digitales, sobre todo de transporte de personas y entrega de productos (Uber, Rappi, Glovo, etc.).

\section{EI proyecto político de una automatización de izquierda}

Las teorías sobre la automatización y el "fin del trabajo" se suelen basar en un análisis en exceso lineal y determinista del desarrollo del capitalismo. En contraste, aquí planteamos, inspirándonos en parte en Marx y en parte en el desenvolvimiento histórico del capitalismo en el último siglo, que este sistema se constituye ciertamente en torno de una tendencia contradictoria vinculada con el aumento de la composición orgánica del capital, pero que sin 
embargo a la vez tiene la capacidad de desarrollar mecanismos para contrarrestarla parcialmente. El tipo de mecanismos adoptados, vale la pena enfatizar, también está condicionado por cuestiones históricas de diferente índole: económicas, poblacionales, naturales, educacionales, ideológicas y políticas. Así, por ejemplo, y en relación con los condicionamientos políticos, señalamos que el capitalismo fordista tenía la necesidad de que grandes franjas de la población se integrasen en formas de organización del trabajo en gran medida alienantes y, además, el sistema tenía que reforzar su legitimidad dado el desafío que representaba, particularmente en materia social, la presencia del socialismo real. Por otro lado, el capitalismo neoliberal hubiera resultado imposible de no haber mediado factores como la derrota de los movimientos de protesta de las décadas anteriores, la desindustrialización de los países desarrollados que debilitó a las organizaciones sindicales y la crisis de la izquierda que se agudizó con la caída de la Unión Soviética.

Agreguemos además que el discurso estándar sobre la automatización, específicamente cuando se plantea desde la izquierda, le hace un paradójico favor al capitalismo neoliberal. Al plantear un supuesto abstracto e inverosímil según el cual este sistema contribuye a una "productividad extrema" que tiende a "un coste marginal cero" (Rifkin, 2014, p. 14) y al centrarse en las dinámicas de sectores tecnológicos de "punta" (grandes empresas de informática, telecomunicaciones, etc.) dotan al capitalismo actual de una vitalidad que es desmentida por las bajas tasas de crecimiento y de aumento de la productividad, además de los bajos salarios, la creciente precariedad y una desigualdad tan exorbitante que tiene parangón con las sociedades del siglo XIX (Piketty, 2014, pp. 353-358), pero que casi ciento cincuenta años después resulta sencillamente injustificable.

En este contexto, lo que hay que revitalizar, nuevamente siguiendo a Marx, es el análisis de la automatización en términos 
de un proyecto ético-político que tienda hacia el poscapitalismo. Pero para esto, hay que hacer una revisión crítica de algunos supuestos de este proyecto. Intentaremos ahora avanzar en esta dirección analizando los planteos de Srnicek y Williams, los redactores del célebre Manifiesto por una política aceleracionista (2017a), y particularmente lo que en su obra posterior, Inventar el futuro (2017b), denominan como "sociedad postrabajo", idea que sintetiza lo que es su proyecto político para la izquierda. Ciertamente, estos autores repiten en buena medida el discurso respecto de que la principal causa del accidentado desempeño del mercado de trabajo en las últimas décadas se encuentra en un supuesto proceso acelerado de automatización. Sin embargo, su mérito descansa en plantear la cuestión en términos de la construcción positiva de un proyecto político que vaya más allá de las tendencias del capitalismo en curso ya que, según consignan, este sistema también frena y contiene el desarrollo tecnológico y la tendencia a la automatización (Srnicek y Williams, 2017a, p. 40). Esta idea tiene sentido considerando la avidez del capitalismo neoliberal por el trabajo precario y mal pago, el cual -como se desprendía del análisis marxiano- ciertamente desincentiva la mejora tecnológica de los procesos productivos. El proyecto que plantean apuntaría a romper progresivamente con la centralidad del trabajo asalariado en la vida social. Para acercarse a este objetivo, los autores expresan una serie de demandas, que ellos entienden, tratando de ir más allá de la dicotomía clásica entre reforma y revolución, como "reformas no reformistas": no rompen directamente con el capitalismo "pero sí prometen liberarnos del neoliberalismo y establecer un nuevo equilibrio de fuerzas políticas, económicas y sociales" (Srnicek y Williams, 2017b, p. 84). Son básicamente tres: 1) Automatización plena de la producción; 2) Reducción de la jornada laboral; 3) Instauración de un ingreso básico universal (IBU). 
A nuestro juicio, este planteamiento resulta pertinente hoy por varias razones. Aunque no compartamos el análisis según el cual la automatización es su principal causa (Srnicek y Williams, 2017b, cap. 5), sí es cierto que el mercado de trabajo, tal como tiende a funcionar hoy en los países capitalistas, es un mecanismo de producción de desigualdad social, en el que particularmente crece el empleo precario y mal pago. La edad de oro del keynesianismo y el pleno empleo parece haber terminado, y nada indica que pueda regresar. Los niveles de crecimiento de la posguerra, una de sus condiciones de posibilidad, son hoy inimaginables, y de hecho todas las proyecciones apuntan a que en el futuro el crecimiento económico seguirá desacelerándose, también en China, que como es sabido hoy impulsa el crecimiento y la demanda globales. La estrategia de compensar la baja tendencial con el aumento de la masa de capital invertida, que vimos que caracterizaba al capitalismo de posguerra, se encuentra así parcialmente bloqueada, lo que también explica la canalización del excedente hacia la esfera financiera. ${ }^{7}$ Autores como Piketty (2014) plantean claramente que, considerando la historia del capitalismo, las condiciones de la posguerra fueron excepcionales y su reedición es imposible, incluso aunque se modificara la lamentable relación de fuerzas entre capital y trabajo hoy existente. Esto, sin sopesar el hecho no menor de que un mayor crecimiento agudizaría la ya precaria situación ecológica, particularmente el problema del cambio climático.

${ }^{7}$ El auge del capital financiero que caracteriza a la etapa actual del capitalismo es antes una consecuencia de los límites que encuentra el capital productivo para expandirse que su causa. Las mismas empresas productivas canalizan buena parte de sus excedentes en esta esfera antes que en la productiva. De hecho, la financiarización de la economía no es -como suponen muchos neokeynesianosuna aberración del actual sistema, sino un mecanismo de compensación y desplazamiento temporal y espacial de sus tendencias críticas. 
En este escenario, se torna indispensable el establecimiento de mecanismos de distribución de la riqueza alternativos al mercado de trabajo que mejoren la situación relativa de los trabajadores, sobre todo los más sujetos a la precarización y la desocupación. Está claro que un ingreso básico universal -siempre y cuando se establezca en un nivel suficiente para una vida digna, como plantean los autores- contribuiría decisivamente a este objetivo, impidiendo que los trabajadores tengan que vender su fuerza de trabajo a cambio de salarios bajos y condiciones laborales precarias. Pero además, está justificada la afirmación de que el IBU es una "reforma no reformista". Aunque los autores la plantean como una reforma a instituir en el marco del capitalismo, sin embargo (y de acá su carácter potencialmente revolucionario) afecta uno de los núcleos de este sistema: el carácter de esa mercancía tan peculiar que es la fuerza de trabajo. Cuando Marx introduce este concepto en El capital, señala con cierta ironía que el capitalista encuentra en el mercado de trabajo al obrero libre "en el doble sentido de que por una parte dispone, en cuanto hombre libre, de su fuerza de trabajo en cuanto mercancía suya, y de que, por otra parte, carece de otras mercancías para vender" (Marx, 2003, p. 205). Con el IBU, ciertamente, la fuerza de trabajo no dejaría de ser una mercancía, pues el obrero sería dueño de su fuerza de trabajo y podría enajenarla (esta es la libertad en el primer sentido señalado por Marx). Pero al tener los medios de vida garantizados por el IBU, el obrero ya no estaría obligado a vender su fuerza de trabajo -es la segunda acepción de la "libertad", y la ironía de Marx apunta justamente a señalar que la misma, en los hechos, se troca en su contrario, es decir, en la falta de libertad por no tener el obrero otra alternativa para la subsistencia- ${ }^{8}$

\footnotetext{
${ }^{8}$ Lo que suele llamarse "derecho al trabajo" (una expresión que recogen casi todas las constituciones nacionales) es una gran falacia. En el capitalismo tal como lo conocemos, el trabajo no es un derecho, no sólo porque para la mayoría
} 
Aunque en la izquierda la propuesta de instituir un IBU cuenta hoy con un respaldo bastante amplio, algunos autores (por ejemplo Clarke, 2017) señalan con escepticismo que más allá de las buenas intenciones de sus propulsores, la implementación del mismo podría terminar siendo contraproducente: si se estableciera en un nivel mínimo, obligaría a las personas a tener que completar sus ingresos con trabajos precarios y terminaría funcionando como un subsidio indirecto al capital. Además, recuerdan que la idea de garantizar algún tipo de renta es apoyada incluso por algunos neoliberales, que en realidad lo que quieren como prenda de cambio es privatizar lo que queda de las instituciones del Estado de Bienestar: el IBU, que aseguraría un ingreso monetario mínimo para ser gastado en el mercado, sería la coartada perfecta para alcanzar este fin. Todo esto es cierto: incluso algunos empresarios y directivos de Silicon Valley -la meca del capitalismo digital y la referencia central de los teóricos de la automatización- defienden

de la población es una obligación de cara a la subsistencia, sino también porque no tiene como correlato la obligación de nadie, estando totalmente sujeto a las condiciones - cada vez más inciertas- del mercado de trabajo. Teniendo en cuenta esta cuestión, en un libro de 1991 André Gorz proponía, en lugar de un ingreso incondicional, instituir una renta básica conjuntamente con el derecho efectivo al trabajo con una jornada laboral reducida (1995, p. 261). Aunque en sus obras posteriores el pensador francés cambió de postura y pasó a defender la incondicionalidad, la suya no era una mala alternativa, sobre todo considerando la densidad que sigue teniendo en el sentido común la ética del trabajo, además de que el trabajo hoy no sólo es el principal vehículo para la obtención de ingresos, sino también para el acceso al reconocimiento social. Srnicek y Williams plantean, con razón, la necesidad de disputar esta ética (2017b, p. 97), pero no hay que perder de vista que la disputa central en lo inmediato es contra una institución que obliga a trabajar para obtener los medios de vida sin garantizar el acceso al trabajo. Tal vez sea mejor dejar que los contornos de la institución superadora de esta situación sean definidos no a priori sino en el terreno de la lucha política, más teniendo en cuenta el espíritu que anima la propuesta de Srnicek y Williams, que como señalaremos a continuación apunta a construir un poder contrahegemónico lo más amplio posible. 
hoy la propuesta, seguramente con la perspectiva de que terminará subsidiando sus servicios digitales y que poco tendrán que aportar para sustentarla, dada su ya probada habilidad para minimizar el pago de impuestos (Morozov, 2018, p. 24). El problema con estas críticas es que asumen que las intenciones del adversario terminarán desfigurando el espíritu original de la propuesta, algo que puede pasar, pero de lo que se trata justamente es de evitarlo, para lo cual lo que se necesita es fuerza política. Por eso, Srnicek y Williams plantean nuevamente con acierto que para llevarla a cabo se necesita la construcción de un poder contrahegemónico amplio, que dispute el sentido común al neoliberalismo (2017b, cap. 7). Se trata, sin lugar a dudas, de una tarea y un desafío enormes, pero que constituye la condición de posibilidad de cualquier transformación, más cuando se reconoce -como hicimos aquí- que el capitalismo, aún encontrándose en una crisis de larga duración, tiene la capacidad de establecer mecanismos de compensación para contrarrestar sus tendencias críticas.

Respecto de la demanda de reducción de la jornada laboral, resulta sin lugar a dudas menos disruptiva, pero no por eso es menos necesaria. La lucha por la reducción de la jornada laboral fue central en el siglo XIX, pero luego de la institución progresiva de la jornada laboral de ocho horas diarias el tema fue perdiendo centralidad en las reivindicaciones colectivas. Como ya señalamos, en el período fordista, los elevados aumentos de la productividad estuvieron acompañados en líneas generales por una mejora de las retribuciones materiales, bajo una lógica a la vez productivista y consumista que tendió a marginar reivindicaciones como la de un mayor tiempo libre. El período neoliberal, como ya sabemos, se caracteriza por una redistribución del ingreso favorable al capital, con salarios generalmente estancados y una jornada laboral que no sólo se mantiene inalterada sino que incluso se incrementa subrepticiamente mediante diversos mecanismos, como señalan 
también Srnicek y Williams (2017b, p. 90). Más allá de los detalles de la propuesta - los autores proponen una semana de cuatro días laborales, en vez de una reducción de la jornada diaria- la justeza del reclamo es difícil de rebatir. Con incrementos de la productividad que han variado en distintos períodos pero han sido más o menos constantes en los últimos cien años, la persistencia de una jornada laboral de ocho horas no muestra si no las dificultades del capitalismo para que la economía del tiempo que en parte impulsa redunde en un aumento del tiempo libre para el conjunto de la sociedad. Este hecho corrobora la justeza del análisis marxiano que ya reseñamos, según el cual el capitalismo es un dispositivo de liberación y recaptura del tiempo bajo la forma de plustrabajo.

La miopía del discurso dominante ante este tema es digna de mención. Por ejemplo, el ya mencionado informe del Banco Mundial refiere al famoso pronóstico de Keynes en 1930 según el cual hacia fines del siglo XX la semana laboral se reduciría a 15 horas, para inmediatamente tacharlo de "falaz" (2016, p. 23). Ciertamente, no caben dudas de que el pronóstico resultaba falaz a la luz de la lamentable realidad del capitalismo actual. Pero no es irrazonable si se lo considera a partir de los aumentos efectivos en la productividad acaecidos desde entonces. En una época cegada por lo que Mark Fisher (2018) denomina "realismo capitalista", la tarea indelegable del pensamiento crítico es poner de manifiesto la irracionalidad de esta realidad, y colaborar así en la construcción de un proyecto contrahegemónico que interrogue el sentido común dominante.

La demanda de "automatización plena de la producción" es, a nuestro juicio, la más problemática. Ciertamente, ya apuntamos que tiene sentido el planteo de Srnicek y Williams según el cual el capitalismo en parte bloquea la tendencia a la automatización, por la difusión del trabajo precario y mal pago, por la utilización de 
regímenes jurídicos - particularmente los vinculados a la propiedad intelectual- que inhiben la difusión de las tecnologías, y por el desinterés por desarrollos tecnológicos que no resultan rentables en el corto plazo, entre otras razones. En síntesis, el desarrollo tecnológico resulta sesgado en el capitalismo porque el imperativo que rige el sistema -la búsqueda de ganancias- es igualmente sesgado. Pero ante esto, un planteamiento que reivindica un camino hacia "la culminación del proyecto de autocrítica y autodominio de la Ilustración" (Srnicek y Williams, 2017a, p. 41), no puede plantear una demanda que descansa en un imperativo tecnológico unidimensional. Si lo que se pretende es que la humanidad recupere el control de su destino, lo que debe ampliarse ante todo es el espacio de deliberación crítica respecto de los fines de la producción. La demanda de "automatización plena de la producción", en cambio, implica establecer un imperativo de eficiencia de cara a liberar tiempo de trabajo, un fin loable que sin embargo no puede ser el criterio único y último. En América Latina, por ejemplo, se viene planteando el debate respecto de los costos humanos y ecológicos que tiene el uso, supuestamente eficiente, de los cultivos transgénicos, la minería a cielo abierto y la explotación de combustibles no convencionales. La economía convencional trata este tipo de consecuencias perniciosas como "externalidades negativas", efectos no queridos del "progreso" sobre los que nadie es responsable. En vistas de un proyecto político superador del estado de cosas existente, estas cuestiones tienen que empezar a ser sopesadas en primer término a la hora de tomar decisiones económicas. Si lo que se quiere es recuperar el proyecto de la ilustración, ante todo hay que aprender del pasado y no recaer en sus errores, que como bien supo la Teoría crítica estaban vinculados con el olvido de los fines y la fetichización de los medios. Estos fines son múltiples como lo es la pluralidad de la vida humana, y también deben ser objeto de reflexión $\mathrm{y}$ 
deliberación colectiva, algo que está en las antípodas de la imposición de un imperativo único, por más importante que sea.

El imperativo de eficiencia que conlleva la demanda de automatización plena pasa por alto un problema que teóricos del "fin del trabajo" como Gorz (1995) sí supieron sopesar: la necesidad de pensar los límites de la propia racionalización del trabajo en el capitalismo. Hay que considerar que existen numerosas actividades humanas en las cuales el imperativo de eficiencia (que en el capitalismo está estrechamente vinculado con el de "rentabilidad") puede atentar -y de hecho lo hace- contra los propósitos de las mismas. En la medicina, por ejemplo, los profesionales son cada vez más presionados por las grandes corporaciones para tratar a los pacientes de modo "eficiente", es decir, empleando el menor tiempo posible. Esto, en muchos casos, tiende a afectar la prestación: el paciente no es considerado una persona singular, sino el ejemplar de un tipo general que hay que categorizar lo antes posible. Esto contribuye a prácticas nocivas, como por ejemplo la medicalización indiscriminada. Estas tendencias se profundizan aún más con las tecnologías digitales, por ejemplo a partir de la utilización de la inteligencia artificial para la realización de diagnósticos. La medicina es sólo un caso: cuestiones similares se pueden plantear respecto a otros sectores muy importantes, como el de la educación. Lo que se olvida es que la economía del tiempo conlleva un proceso de estandarización, que llevado a un extremo no es inocuo en la prestación de ciertos servicios a las personas como podría serlo en la producción de bienes materiales. Srnicek y Williams apenas rozan este problema cuando reconocen que ciertas tareas, particularmente las de cuidado -crianza de niños por ejemplo- pueden plantear "límites morales" al principio general de la automatización (2017b, pp. 88-89). Aquí entendemos que es una cuestión bastante más general e importante, y que además no es sólo moral sino también política. En el marco 
de una "sociedad postrabajo", las personas van a tener más tiempo, y más allá del ocio van a querer seguir realizando actividades útiles, y la pregunta que se abre entonces es cuáles son aquellas que deberían ser encargadas a los seres humanos. Esto vuelve a traer la compleja pregunta -que la sociedad actual evita al transformar todo en un medio para adquirir un ingreso- respecto de los fines que persiguen las tareas que realizamos, y los mejores modos para alcanzarlos, desde una perspectiva amplia que no reduzca todo al ahorro del tiempo dedicado.

Esto que estamos planteando está estrechamente vinculado con otro problema: la tecnología tampoco es neutral, sino que en ella se materializan propósitos y valores ético-políticos (Feenberg, 2012). Resulta llamativo que Srnicek y Williams reconozcan este hecho cuando plantean la necesidad de disputar la tecnológica, hoy hegemonizada por los intereses del capitalismo (2017b, pp. 113119), pero que eso no los llame a revisar críticamente el imperativo de automatización plena. La cuestión es incluso más importante considerando en particular los desarrollos tecnológicos actuales en inteligencia artificial, que se basan en la recolección masiva de datos, la cual plantea problemas serios para la privacidad de las personas, con el agravante de que el big data hoy es monopolizado por un pequeño grupo de empresas tecnológicas. Y, lo que es aún más inquietante, el Machine learning implica, como plantean Rouvroy y Berns (2016), una forma de "gubernamentalidad algorítmica" que apunta a capturar la atención de los sujetos y a condicionar de un modo conductista -dirigiéndose a las pulsiones inconscientes- sus comportamientos. El análisis algorítmico permite construir un saber basado en la correlación estadística de datos, y este saber es utilizado por las grandes corporaciones en general con propósitos comerciales, independientemente de la voluntad y el conocimiento de los sujetos. Ningún proyecto que tenga como horizonte el autodominio de las personas sobre sus 
condiciones de existencia puede aceptar acríticamente esta tecnología, sino que tiene que replantearla de modo tal que, en lugar de obturar, favorezca y potencie la reflexividad de los sujetos.

\section{Conclusión}

En 1991, apenas un par de años después de la caída del muro de Berlín, André Gorz planteaba:

la condición del hombre post-marxista es que el sentido que Marx leía en el desarrollo histórico sigue siendo para nosotros el único sentido que el desarrollo puede tener, pero que tenemos que perseguir este sentido independientemente de la existencia de una clase social capaz de hacerlo realidad (1995, p. 128).

Treinta años después, el diagnóstico del pensador francés mantiene, a nuestro juicio, plena vigencia. El sentido que para Marx tenía el desarrollo histórico, al menos el acontecido bajo el primado del sistema capitalista, radicaba en que el impulso de las fuerzas productivas en este sistema -traumático para una parte mayoritaria de la población- desembocaba finalmente en una organización social radicalmente diferente, en la cual el tiempo de trabajo necesario, al igual que la riqueza generada y el tiempo libre disponible, pasaban a distribuirse racional y equitativamente en una comunidad que dejaba atrás la lucha encarnizada e individualista por la existencia.

La historia del siglo XX interrogó algunas de las premisas del planteo marxiano que otorgaban una objetividad inexorable a este destino histórico. El capitalismo keynesiano-fordista puso de manifiesto la capacidad del sistema para reestructurarse y sostenerse frente a las tendencias a la crisis - la baja tendencial de la tasa de ganancia, por ejemplo- a la vez que consiguió integrar en la sociedad de consumo a amplias capas de la población antes apenas 
adiestradas en el trabajo y la subsistencia -situación que, sin embargo, estuvo lejos de ser universal, atendiendo por ejemplo a la condición de muchos países periféricos que continuaron siendo fuente del despojo colonial-imperialista-. Incluso así, la precaria estabilidad de este capitalismo también terminaría agotándose. En el capitalismo neoliberal, las tasas de ganancia parecen mantenerse al precio de una precarización creciente de las condiciones de existencia y una concentración de la riqueza que sigue en aumento año a año. A la vez, la clase trabajadora -cuya homogeneización nunca aconteció como en principio esperaba Marx- es fragmentada en líneas que siguen tanto la división internacional del trabajo (con la deslocalización parcial de la industria en los países del sudeste asiático, por ejemplo) como unos mercados de trabajo cada vez más duales, donde el empleo en el sentido dominante en la etapa keynesiano-fordista se reduce mientras crece el contingente de los desocupados, precarizados y tercerizados.

El interés de los discursos contemporáneos sobre la automatización estriba, precisamente, en que recuperan esa dimensión emancipatoria que para Marx tenía el desarrollo histórico. Y esto, en un contexto en el cual, además de no haber un actor social preestablecido para llevar a cabo un proyecto postcapitalista (como señalaba Gorz), incluso se han esfumado ideas como las de "futuro", "proyecto", etc. El capitalismo neoliberal instituye una suerte de presente eterno, signado por la competencia encarnizada para unos y la penuria sin motivo ni sentido para otros. El futuro, mientras tanto, aparece teñido de peligros (el cambio climático, la crisis sanitaria, el desastre nuclear, la guerra bacteriológica) antes que de esperanzas y proyectos. En este escenario, la necesidad de recuperar la idea de un proyecto político a futuro es el punto fuerte del discurso actual sobre la automatización, cuestión que el Aceleracionismo de izquierda, acertadamente, pone en un primer plano. Justamente en vistas de 
afianzar este punto fuerte, en este artículo hemos procedido tratando de revisar algunas flaquezas que suelen acompañar a estos discursos.

Así, por un lado, discutimos el carácter simplista que tienen los análisis corrientes sobre el desempleo tecnológico. Por el contrario, aquí mostramos que el capitalismo actual se caracteriza por unas tasas de aumento de la productividad notablemente más bajas que en el período de auge del pleno empleo en la posguerra, por lo cual la compleja dinámica del mercado de trabajo contemporáneo no puede explicarse por esa variable considerada aisladamente. Por otro lado, y en lo que hace ya no al diagnóstico sino al proyecto político de la automatización, planteamos -discutiendo en particular con la propuesta de Srnicek y Williams de automatizar completamente la producción- la necesidad de evitar visiones ingenuas sobre la tecnología, considerándola críticamente a la luz tanto de su dimensión ético-política como de la pluralidad de fines que debería sopesar una propuesta con pretensiones de emancipación. En uno y otro caso, los desarrollos aquí realizados apuntan menos a proveer conclusiones definitivas que a aportar elementos para enriquecer una discusión que promete estar cada vez más presente en el futuro.

\section{Referencias}

Antunes, R. (2005). Los sentidos del trabajo. Herramienta. Arboleda, M. (2020). Planetary Mine: Territories of Extraction under Late Capitalism. Verso.

Aristóteles (2000). Política. Gredos.

Arntz, M., Gregory, T. y Zierahn, U. (2016). The Risk of Automation for Jobs in OECD Countries: A Comparative Analysis. 
OECD Social, Employment and Migration Working Papers, 189. OECD Publishing.

Autor, D. H. (2015). Why are there still so many jobs? The history and future of workplace automation. Journal of Economic Perspectives, 29(3), 3-30.

BANCO MUNDIAL (2016). Informe sobre el desarrollo mundial 2016: Dividendos digitales. Banco Mundial.

Benanav, A. y Clegg, J. (2010). Misery and debt: on the logic and history of surplus populations and surplus capital. En Pendakis, A. et al. (Eds.), Contemporary Marxist Theory: An Anthology (pp. 585-608). Bloomsbury.

Benanav, A. (2019). La automatización y el futuro del trabajo - I. New Left Review, 119, 7-44.

Benanav, Aaron (2020), La automatización y el futuro del trabajo II. New Left Review, 120, 125-158.

Boltanski, L. y Chiapello, È. (2002). El nuevo espiritu del capitalismo. Akal.

Caffentzis, George (2020). En letras de sangre y fuego. Tinta Limón.

Castells, M. (2005). La era de la información. Vol. 1: La sociedad red. Alianza.

Castells, M. (2006). La era de la información. Vol. 3: Fin de Milenio. Alianza.

Coriat, B. (2001). El taller y el cronómetro. Ensayo sobre el taylorismo, el fordismo y la producción en masa. Siglo XXI.

Clarke, J. (2017). Basic Income: Progressive Dreams Meet Neoliberal Realities. The Bullet.

https://socialistproject.ca/2017/01/b1350

Feenberg, A. (2012). Transformar la tecnología. Una nueva visita a la teoría crítica. Universidad Nacional de Quilmes. 
Figueroa, V. (2019). ¿Hacia el fin del trabajo? Mitos, verdades y especulaciones. Nueva Sociedad, 279, 49-61. https://nuso.org/articulo/hacia-el-fin-del-trabajo/ Fisher, M. (2018). Realismo capitalista. Caja Negra.

Frey, C. y Osborne, M. (2013). The Future of Employment: How Susceptible Are Jobs To Computerisation? Universidad de Oxford. https://www.oxfordmartin.ox.ac.uk/downloads/academic/The_Futu re_of_Employment.pdf

GORZ, André (1995). Metamorfosis del trabajo. Sistema.

Habermas, J. (1998). Teoría y praxis. Altaya.

Harvey, D. (2008). La condición de la postmodernidad. Amorrortu.

Dyer-Witheford, N., Kjøsen, A. y Steinhoff, J. (2019). Inhuman Power: Artificial Intelligence and the Future of Capitalism. Pluto Press.

Marx, K. (2001). Elementos fundamentales para la crítica de la economía política (Grundrisse) 1857-1858 (3 volúmenes). Siglo XXI.

Marx, K. (2003). El capital, Tomo I: El proceso de producción del capital. Siglo XXI.

Marx, K. (2007). El capital, Tomo III: El proceso global de la producción capitalista. Siglo XXI.

Morozov, E. (2018). Introducción. En Capitalismo Big Tech. ¿Welfare o neofeudalismo digital? (pp. 13-38). Enclave de libros.

https://www.museoreinasofia.es/sites/default/files/actividade s/programas/cuaderno_de_trabajo_1_morozov.pdf OCDE (2015). El Futuro de la Productividad. Nota conjunta de política del Departamento de Asuntos Económicos y de la Dirección de Ciencia, Tecnología e Innovación. https://www.oecd.org/economy/growth/El-futuro-de-laproductividad.pdf 
OCDE (2019). Compendion of Productivity Indicators 2019 https://www.oecd.org/sdd/productivity-stats/oecd-compendium-ofproductivity-indicators-22252126.htm

Piketty, T. (2014). El capital en el siglo XXI. Paidós.

Rapoport, M. y Brenta, N. (2010). Las grandes crisis del capitalismo contemporáneo. Capital Intelectual.

Robinson, J. (1973). Marx y Keynes. En Economía de mercado versus economía planificada. Ediciones Martínez Roca.

Rifkin, J. (1996). El fin del trabajo. Paidós.

Rifkin, Jeremy (2014). La sociedad del coste marginal cero.

Paidós.

Roucroy, Antoinette y Berns, Thomas (2016). Gubernamentalidad algorítmica y perspectivas de emancipación: ¿la disparidad como condición de individuación a través de la relación? Adenda filosófica, 1, 87-116.

Williams, A. y Srnicek, N. (2017a). Manifiesto por una política aceleracionista. En Avanessian, A. y Reis, M. (comps.), Aceleracionismo (pp. 33-48). Caja Negra.

Williams, A. y Srnicek, N. (2017b). Inventar el futuro: postcapitalismo y un mundo sin trabajo. Malpaso. 



\section{SECCIÓN BIBLIOGRÁFICA / REVIEWS}


